\title{
Socioeconomic disparities in school absenteeism after the first wave of COVID-19 school closures in Scotland*
}

Edward Sosu and Markus Klein

University of Strathclyde, UK

January 14, 2021

\section{Key Points}

- Student absences after the first wave of Covid-19 school closures were higher than in previous years

- Higher rates of absenteeism after school lockdown were due to COVID-19 related reasons

- Overall, non-Covid-19-related absence rates are similar to trends observed in earlier years

- Socioeconomic inequalities in school absenteeism were higher post-lockdown than in previous years

- This increase can be attributed to rising disparities in school absenteeism due to Covid-19-related and non-Covid-19 reasons

- The rise in socioeconomic inequality in non-Covid-19related absenteeism was not only due to higher absence rates among students from the most deprived areas but also due to lower absence rates among students from the least deprived areas

- Addressing the disproportionate short- and long-term impact of the pandemic on the most vulnerable children needs to be at the forefront of policy agenda

- We need greater monitoring and evaluation of

$\circ$ inequalities in home learning during the second round of school closures

$\circ$ inequalities in academic achievement after school reopening

$\circ$ policy interventions designed to mitigate the consequences of Covid-19 on achievement gaps.

\footnotetext{
* This study is funded by the Economic and Social Research Council (ESRC) Secondary Data Analysis Initiative Award ES/R004943/1. We thank Adam Naylor who kindly provided us with the attendance and absence data collected after schools reopened.
} 
School attendance is crucial for children's educational attainment (e.g., Ansari \& Pianta, 2019) and particularly for children from lower socioeconomic backgrounds (Ready, 2010). During the Covid-19 school closures, socioeconomic inequalities in engagement with home learning have exacerbated (Andrew et al., 2020; Kuhfeld et al., 2020; The DELVE Initiative, 2020), which likely led to an increase in disparities in educational achievement (Engzell, Frey \& Verhagen, 2020). To reduce further learning loss and mitigate socioeconomic gaps in achievement and wellbeing for all children, governments around the world reopened schools immediately after the first wave of Covid-19 pandemic (Scottish Government, 2020a\&b; DFE, 2020; Bryant, Dorn, Hall, \& Panier, 2020; Barton \& Parekh, 2020).

In Scotland, a key approach to reopening schools and containing the spread of the virus required that children self-isolate if they test positive for Covid-19, show any symptoms of Covid-19, or have a close family member who tests positive for the virus (Scottish Government, 2020b; NHS Test and Protect, 2020). However, findings from Covid-19 infection rates across subgroups show that individuals living in socioeconomically deprived areas are more likely to be exposed to the virus than individuals in less deprived areas (Public Health Scotland, 2020; Lone et al., 2020; National Records of Scotland, 2021). This means that children from lower socioeconomic backgrounds and family members in their households are at a higher risk of infection and at a higher risk of self-isolating from school. In other words, children from disadvantaged backgrounds are more likely to miss a greater proportion of school because of Covid-19-related reasons. This, in addition to preexisting socioeconomic gaps in school absenteeism (Klein, Sosu \& Dare, 2020; Klein, Goodfellow, Dare \& Sosu, 2020), exacerbates socioeconomic inequalities in school attendance, and likely, educational achievement (Sosu \& Ellis, 2014). Hence, Covid-19 may not only have increased socioeconomic achievement gaps during lockdown but may continue to do so via school attendance disparities when schools reopened. 
In our previous research brief on socioeconomic differences in school attendance (Klein, Goodfellow, Dare \& Sosu, 2020), we called to monitor socioeconomic inequalities in school attendance after the Covid-19-related school closures. Although a UK-wide report indicates that initial school attendance in Scotland after school reopening was comparatively high (Sibieta, 2020), it is crucial to monitor the development of socioeconomic disparities in school attendance after the first Covid-19 lockdown.

This report examines trends in school attendance in Scotland following school reopening and investigates whether there are socioeconomic differences in school absences due to Covid-19-related and non-Covid-19 reasons.

\section{Data}

For this research brief, we used administrative data on daily school attendance in Scotland after the school lockdown from $17^{\text {th }}$ August 2020 to $4^{\text {th }}$ December 2020 (last access date: $11^{\text {th }}$ December 2020). In their Covid-19 weekly updates, the Scottish Government also reports school attendance data by pupil characteristics

\section{(https://public.tableau.com/profile/sg.eas.learninganalysis\#!/vizhome/COVID19-}

SchoolsandChildcareInformation/Introduction). The percentage of pupils attending school relates to the total number of possible attendances. The data allow us to differentiate between absences due to Covid-19-reasons and absences due to non-Covid-19-related reasons. Socioeconomic information was measured using Scottish Index of Multiple Deprivation (SIMD) quintiles with SIMD 1 representing children from $20 \%$ of the most deprived areas in Scotland and SIMD 5 children from $20 \%$ of the most affluent areas.

To compare school absenteeism trends with previous years, we used biennial yearly attendance rates from 2006/07 to 2018/19 (https://www.gov.scot/publications/schoolattendance-and-absence-statistics/). Attendance rates by SIMD were only available from 2012/13. 
There are three key caveats for interpreting the findings. First, daily attendance data were only available after the first Covid-19-related school closures, and comparable data do not exist before the first lockdown. Second, for previous years, data are only publicly available as yearly averages and biennially. Since our post-lockdown data covers school attendance only after the summer holidays, it is strictly not comparable to previous annual attendance rates. As a result, while data inclusion from previous years helps to examine trends, care is needed when drawing conclusions. Third, the analysis presented includes attendance data for both primary and secondary pupils because attendance by SIMD was only available for primary and secondary students combined. Therefore, it is not possible to examine trends in socioeconomic disparities in school attendance separately for primary and secondary pupils.

\section{Findings}

\section{Overall, Covid-19-related and Non-Covid-19 school absenteeism}

Trends in overall school absences (Figure 1) indicate that the rate of absence after the first wave of Covid-19 school closures (average 9.4\%) was higher than in previous years (average 6.7\%). Fluctuations characterised trends in school absenteeism throughout the period with increased absenteeism in the later part of the school term. Interestingly, the school absence rate was substantially lower in the first week of school reopening compared to previous years $(4.6 \%)$. An initial increase in absences during week two and three after reopening may be due to a cautious approach adopted by schools during the first three weeks in interpreting government's guidance that "people who are ill stay at home" (Scottish Government 2020a, p.6).

The decomposition of overall absences post-school closures by Covid-19-related (average 2.8\%) and non-Covid-19 reasons (average 6.6\%) in Figure 2 suggests that the observed increase in overall school absences was due to Covid-19-related reasons. While constant fluctuations were observed in non-Covid-19-related school absences that are roughly at the same rate as in previous years, there was a steady increase in Covid-19-related absences 
after the initial decrease from the peak in weeks two and three (albeit with a slight decrease in the last weeks). In other words, Covid-19 exacerbated school absenteeism rates for children in primary and secondary schools in Scotland.

Figure 1. Absence rates pre- and post-school closures

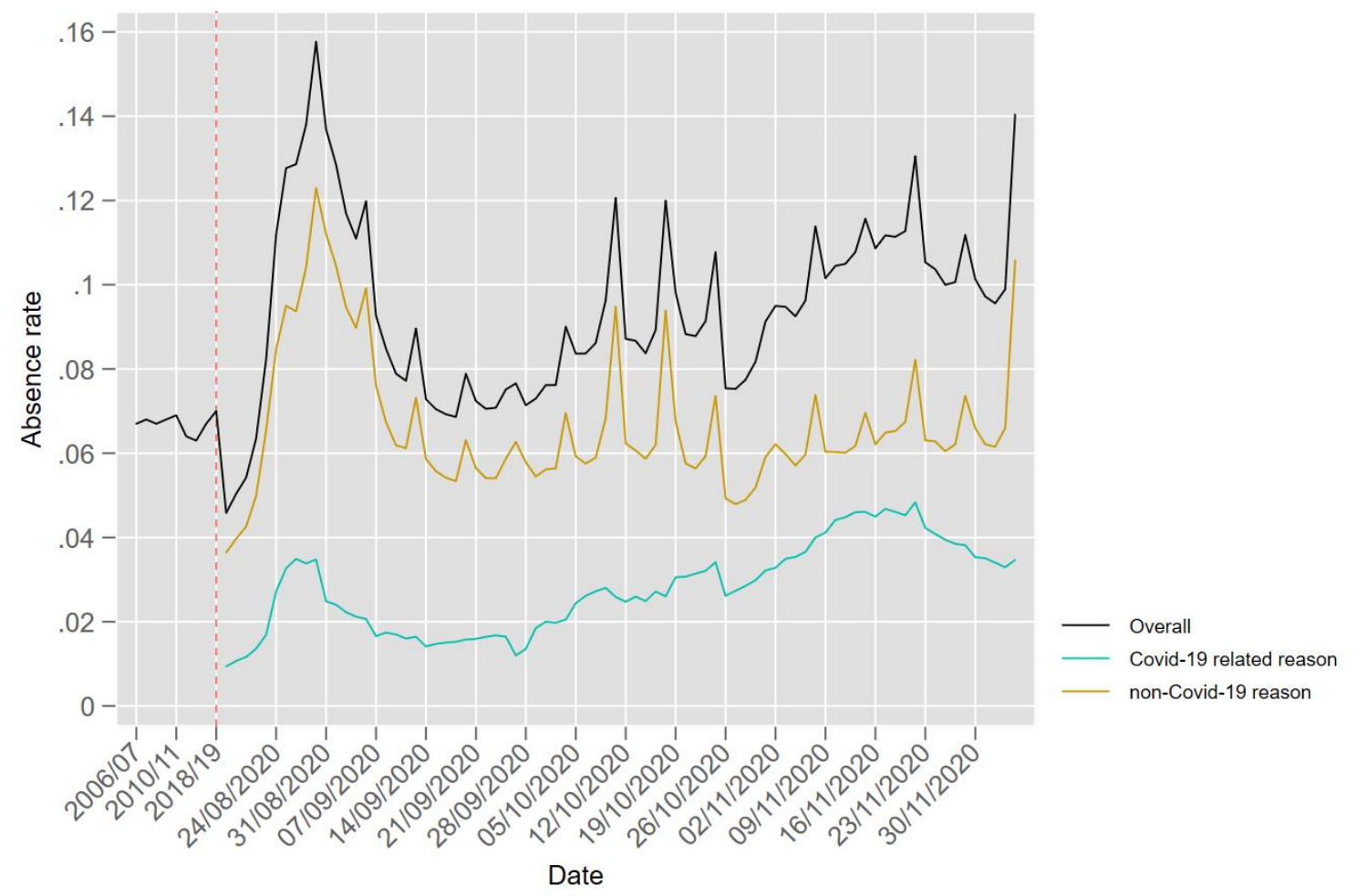

\section{Overall absences by socioeconomic characteristics}

The analysis of socioeconomic differences in overall absenteeism indicates that students from disadvantaged socioeconomic areas were more likely to be absent following school return than their more affluent peers. By the first week of December when our final data were recorded, the absence rate for students from the most deprived quintile (SIMD 1) was $21 \%$ compared to about $8 \%$ for those from the most affluent quintile (SIMD 5). Socioeconomic disparities were at its smallest in the first week in August following the reopening of schools (SIMD 1 average $=8.3 \%$, SIMD 5 average $=4.0 \%$; difference 4.3 percentage points) 
Figure 2. Overall absence rates by SIMD post-school closures

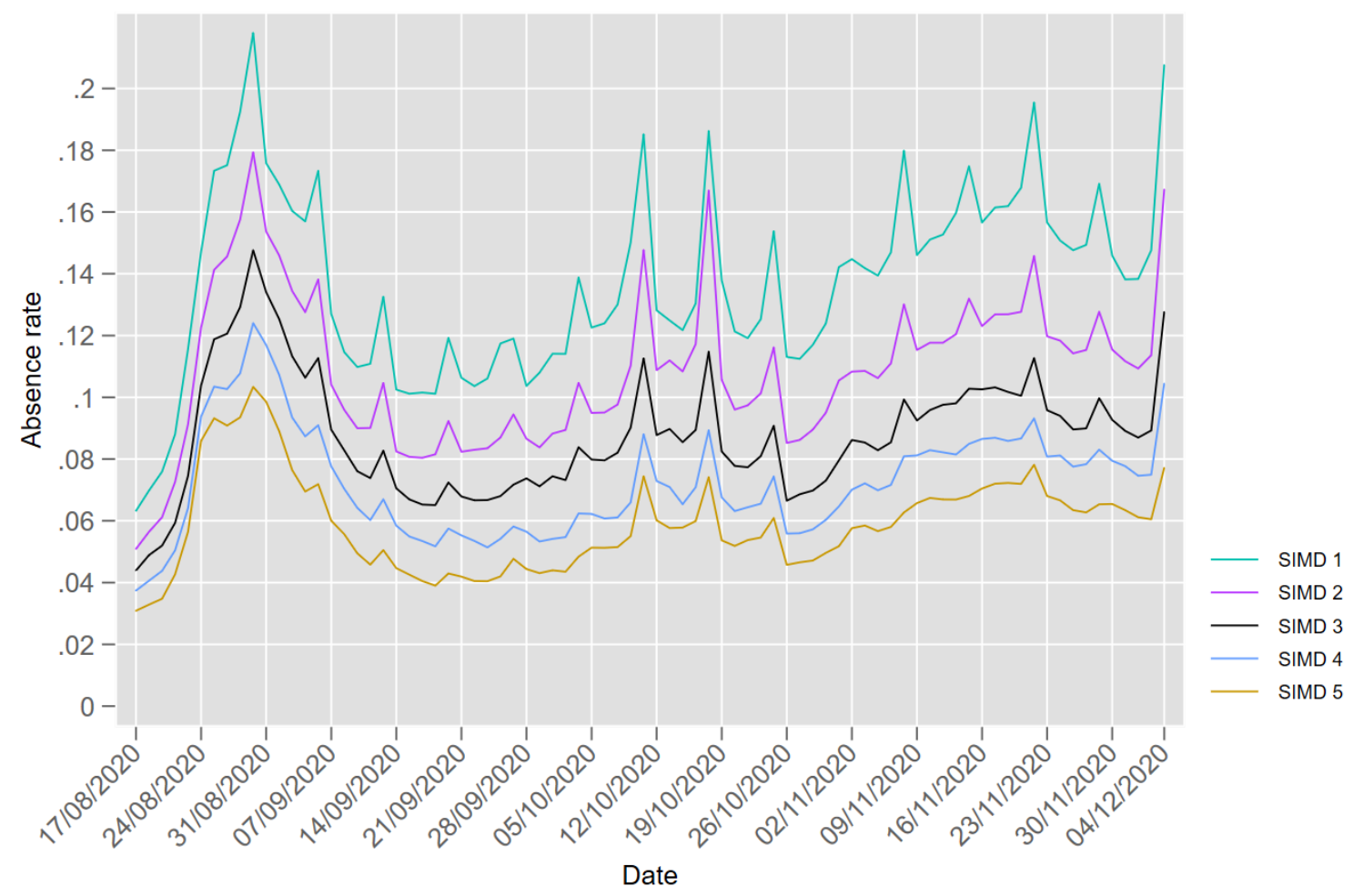

\section{Covid-19-related and non-Covid-19 absenteeism by socioeconomic characteristics}

There were socioeconomic differences in school absenteeism due to Covid-19-related and nonCovid-19 reasons (Figure 3). While the extent of socioeconomic disparities in absences due to non-Covid-19 reasons (right-hand graph) fluctuated post-lockdown (SIMD 1 average $=9.8 \%$, SIMD 5 average $=3.9 \%$, difference 5.9 percentage points), inequalities in absences due to Covid-19-related reasons became stronger over time. While socioeconomic differences in absence rates due to Covid-19-related reasons were already existent up until the end of October (SIMD 1 average $=3.1 \%$, SIMD 5 average $=1.6 \%$, difference 1.5 percentage points $)$, they grew stronger since the beginning of November $($ SIMD 1 average $=5.8 \%$, SIMD 5 average $=$ $2.9 \%$, difference 2.9 percentage points). Hence, the risk for students from the most deprived areas to miss school due to Covid-19-related reasons was twice as high as for students from the least deprived areas in this period. 
Figure 3. Absences due to COVID-19-related reasons and non-COVID-19-reasons by SIMD
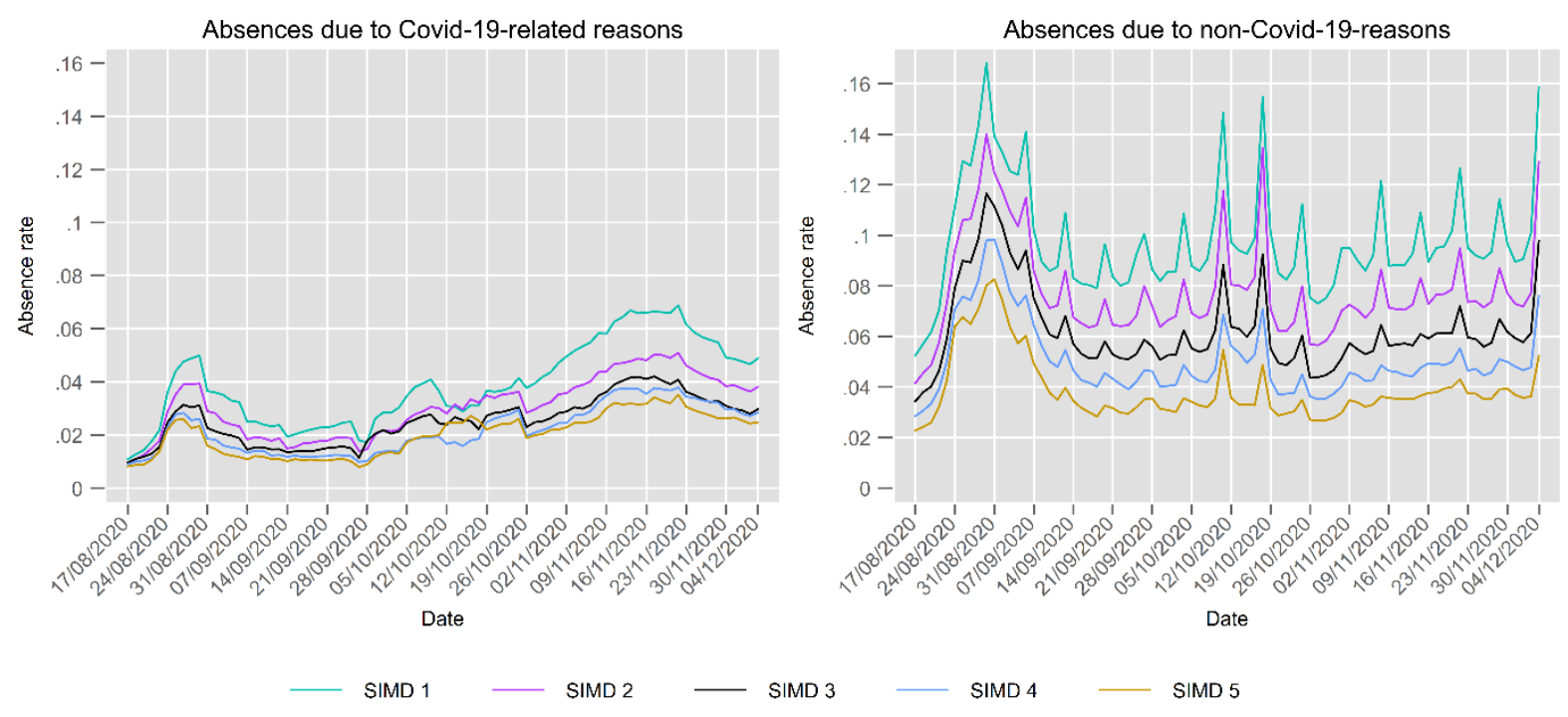

To examine whether socioeconomic disparities in school absences after the first lockdown vary with previous years, we drew a comparison with earlier data on socioeconomic differences in attendance. Figure 4 shows absence rates by SIMD 1 and SIMD 5 pre- and post-school closures and the risk difference in absences between students from the most (SIMD 1) and least deprived quintile (SIMD 5).

The figure's upper graph illustrates that absences increased for both groups post-school closure but that the increase was much stronger for disadvantaged students (SIMD 1). Accordingly, the risk difference (lower graph) increased substantially between 2018/19 (4.9 percentage points) and the observation period post-lockdown (average 7.8 percentage points). As expected, a socioeconomic gap in absences due to Covid-19-related reasons contributes to this increase in inequalities in overall absences. However, the lower graph also illustrates a rise in the risk difference between students living in deprived areas (SIMD 1) and non-deprived areas (SIMD 5) due to non-Covid-19 reasons post-school closures. In other words, the increase in inequalities in overall absences is due to socioeconomic disparities in Covid-19-related absences and an increase in disparities in "conventional" absences. Interestingly, increasing disparities due to non-Covid-19 reasons compared to previous years are due to an increase in 
absence rates among students in SIMD 1 and a decrease in absence rates among students in SIMD 5.

Figure 4. Absence rates by SIMD 1 (most deprived) and SIMD 5 (least deprived) pre- and post-school closures and risk difference in absence
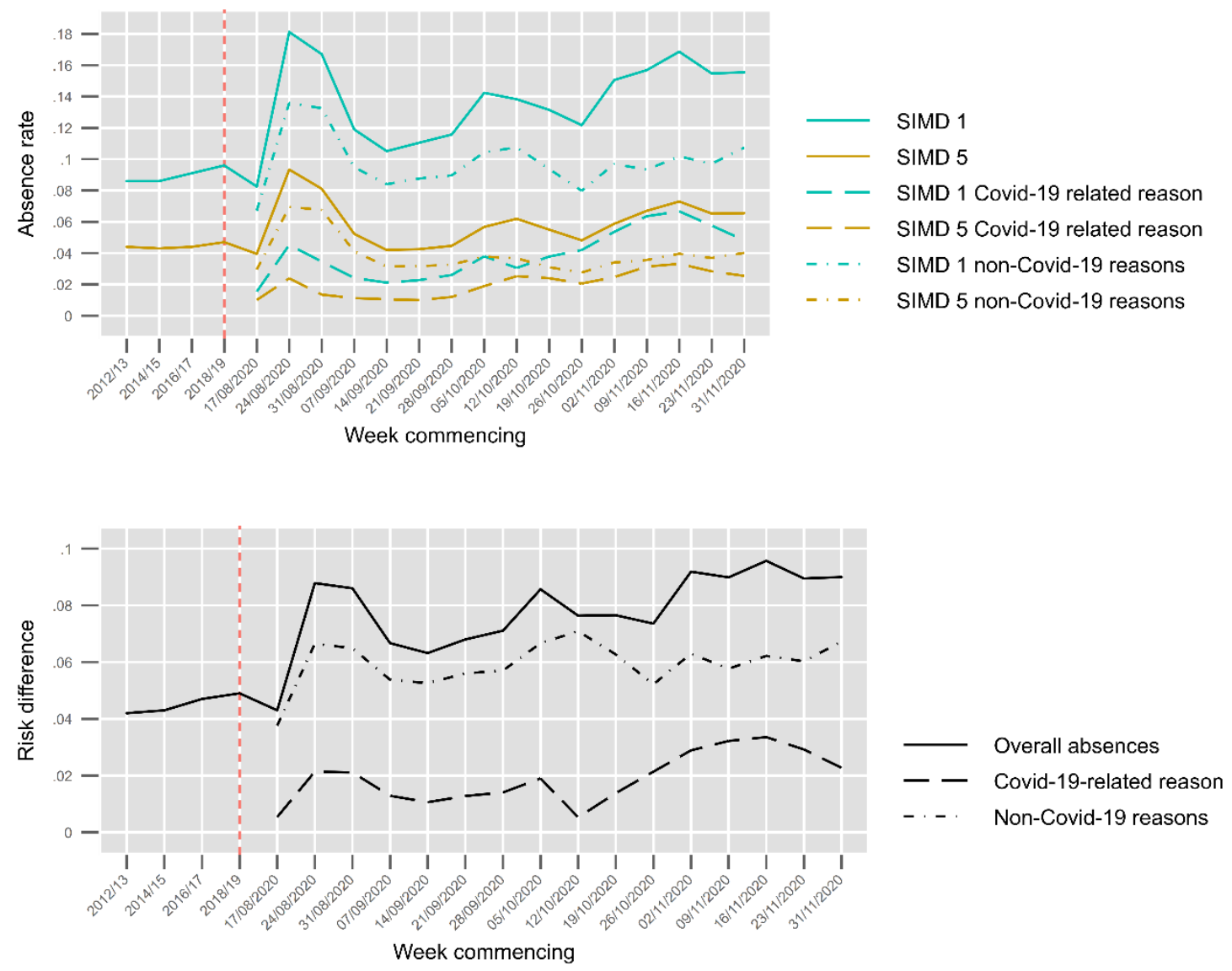

\section{Conclusion and implications}

We examined trends in school attendance in Scotland after the first wave of Covid-19 school closures and investigated whether there were socioeconomic disparities in school absences due to Covid-19-related and non-Covid-19 reasons. Our findings indicate that overall absence rate after the first wave of lockdown was about 2.7 percentage points higher than in previous years. This increase was mainly due to Covid-19 related absences. Non-Covid-19 absence rates were similar to those in previous years.

Consistent with our expectations, there were socioeconomic inequalities in both Covid19-related and non-Covid-19 school absenteeism. The disproportionate health impact of 
Covid-19 on those from disadvantaged backgrounds (e.g., Lone et al., 2020), and unequal impact on children's learning and wellbeing during the lockdown (e.g., Andrew et al., 2020) extends to inequalities in school attendance after the lockdown.

Socioeconomic disparities in school absenteeism post-lockdown were stronger than in previous years. This is not surprising given the socioeconomic inequalities in absences due to Covid-19. However, socioeconomic differences in absence rates also increased for non-Covid19 reasons compared to previous years. This was due to a somewhat higher non-Covid-19related absenteeism among students in the most deprived areas but also due to a lower absenteeism among students in the most affluent areas. Hence, the latter attended school more regularly after lockdown than they did in previous years.

From the above presented evidence, we can conclude that the education of children from disadvantaged backgrounds did not only suffer during school lockdown but was also adversely affected through more frequent school absences after the lockdown. Given the detrimental impact of school absenteeism for academic achievement (e.g., Gottfried, 2010), the consequences for inequalities in educational achievement from these patterns of findings are likely to be huge. Addressing the disproportionate short- and long-term impact of the pandemic on the most vulnerable children needs to be at the forefront of the education policy agenda. Long-term policies that mitigate the detrimental impact of Covid-19 on socioeconomic inequalities in educational attainment are needed.

When finalising this report, the reopening of schools in Scotland and the rest of the UK was postponed due to increases in Covid-19 infections. This new lockdown may again exacerbate socioeconomic inequalities in learning and further alienate children from lower socioeconomic backgrounds from schooling once they are allowed to go back. There is a need to closely monitor disparities in children's learning during this period and post-lockdown absences. . Notably, the robust evaluation of policy interventions to help mitigate educational 
inequalities arising from Covid-19 is required. This will also provide insights on the effectiveness of interventions put in place and the extent to which it mitigates growing Covid19-related socioeconomic inequalities in learning and achievement. 


\section{References}

Andrew et al., (2020). Learning during the lockdown: real-time data on children's experiences during home learning. IFS Briefing Note BN288. Retrieved from https://www.ifs.org.uk/publications/14848

Ansari, A., \& Pianta, R. C. (2019). School absenteeism in the first decade of education and outcomes in adolescence. Journal of School Psychology, 76(July), 48-61.

https://doi.org/10.1016/j.jsp.2019.07.010

Barton, T. \& Parekh, A. (2020) "Reopening Schools: Lessons from Abroad," To the Point (blog), Commonwealth Fund. https://doi.org/10.26099/yr9j-3620

Bryant, J. Dorn, E., Hall, S. \& Panier, F. (2020). Safely back to school after coronavirus closures. Retrieved from https://www.mckinsey.com/industries/public-and-social-sector/ourinsights/safely-back-to-school-after-coronavirus-closures

Department for Education (2020). Why we are prioritising attendance at school and college. Retrieved from https://dfemedia.blog.gov.uk/2020/12/30/why-we-are-prioritising-attendanceat-school-and-college/

Engzell, P., Frey, A., \& Verhagen, M. D. (2020, October 29). Learning Inequality During the Covid-19 Pandemic. https://doi.org/10.31235/osf.io/ve4z7

Gottfried, M. A. (2010). Evaluating the relationship between student attendance and achievement in urban elementary and middle schools: An instrumental variables approach. American Educational Research Journal, 47(2), 434-465.

https://doi.org/10.3102/0002831209350494

Klein, M., Sosu, E. M. \& Dare, S. (2020). Mapping inequalities in school attendance: the relationship between dimensions of socioeconomic status and forms of school absence. Children and Youth Services Review, 118, 105432 https://doi.org/10.1016/j.childyouth.2020.105432

Klein, M., Goodfellow, C., Dare, S., \& Sosu, E. (2020). Socioeconomic Inequalities in School Attendance in Scotland: Research Brief. University of Strathclyde. Retrieved from https://pureportal.strath.ac.uk/files/107303630/Klein_etal_UoS_2020_Socioeconomic_Inequ alities_in_School_Attendance_in_Scotland.pdf

Kuhfeld, M. Soland, J., Tarasawa, B., Johnson, A., Ruzek, E., \& Liu, J. (2020). Projecting the potential impact of COVID-19 school closures on academic achievement. Educational Researcher, 49(8), 549-565. https://doi.org/10.3102/0013189X20965918

Lone, N. I. et al. (2020). Influence of socioeconomic deprivation on interventions and outcomes for patients admitted with COVID-19 to critical care units in Scotland: A national cohort study. The Lancet Regional Health - Europe, 100005 https://doi.org/10.1016/j.lanepe.2020.100005 
National Records of Scotland (2021). Deaths involving coronavirus (COVID-19) in Scotland: Week 53. Retrieved from https://www.nrscotland.gov.uk/files//statistics/covid19/coviddeaths-report-week-53.pdf

NHS Test and Protect (2020). Test and Protect is Scotland's approach to preventing the spread of coronavirus in the community. Retrieved from https://www.nhsinform.scot/campaigns/test-and-protect

Public Health Scotland (2020). What explains the spatial variation in COVID-19 mortality across Scotland? Retrieved from https://www.publichealthscotland.scot/media/2814/spatialvariation-in-covid-19-mortality-in-scotland-english-september2020.pdf

Ready, D. D. (2010). Socioeconomic disadvantage, school attendance, and early cognitive development: The differential effects of school exposure. Sociology of Education, 83(4), 271286. https://doi.org/10.1177/0038040710383520

Scottish Government (2020a). Wellbeing of pupils to be prioritised. Retrieved from https://www.gov.scot/news/wellbeing-of-pupils-to-be-prioritised/

Scottish Government (2020b). Coronavirus (COVID-19): Guidance on preparing for the start of the new school term in August 2020. Edinburgh: Scottish Government. Retrieved from https://www.gov.scot/publications/coronavirus-covid-19-guidance-preparing-start-newschool-term-august-2020-version-2/

Sibieta, L. (2020). School attendance rates across the UK since full reopening. Education Policy Institute. Retrieved from https://epi.org.uk/publications-and-research/schoolattendance-rates-across-the-uk-since-full-reopening-november/

Sosu, E. \& Ellis, S. (2014). Closing the Attainment Gap in Scottish Education. Retrieved from: https://www.jrf.org.uk/sites/default/files/jrf/migrated/files/education-attainmentscotland-full.pdf

The DELVE Initiative (2020), Balancing the Risks of Pupils Returning to Schools. DELVE Report No. 4. Published 24 July 2020. Retrieved from https://rsdelve.github.io/reports/2020/07/24/balancing-the-risk-of-pupils-returning-to-schools.html. 